\title{
Publisher's Note: Facile Anhydrous Proton Transport on Hydroxyl Functionalized Graphane [Phys. Rev. Lett. 118, 186101 (2017)]
}

Abhishek Bagusetty, Pabitra Choudhury, Wissam A. Saidi, Bridget Derksen, Elizabeth Gatto, and J. Karl Johnson (Received 24 May 2017; published 6 June 2017)

DOI: 10.1103/PhysRevLett.118.239901

This paper was published online on 3 May 2017 with a typographical error in the author list. The third author's name should read as "Wissam A. Saidi." The author name has been corrected as of 25 May 2017. The author name is incorrect in the printed version of the journal. 